\title{
A CASE OF RARE BLOOD GROUP IN OBSTETRIC EMERGENCY
}

\author{
Sudha R1', Lokeshchandra H. C², Manjunath B. S3, Priya Ranganath ${ }^{4}$
}

\section{HOW TO CITE THIS ARTICLE:}

Sudha R, Lokeshchandra H. C, Manjunath B. S, Priya Ranganath. "A Case of Rare Blood Group in Obstetric Emergency". Journal of Evolution of Medical and Dental Sciences 2014; Vol. 3, Issue 34, August 11;

Page: 9028-9030, DOI: 10.14260/jemds/2014/3163

ABSTRACT: We present a rare case of an A2B +ve blood group with obstetric hemorrhage in mild hypovolemic shock with DIC. An emergency request for blood transfusion confounded the blood bank officer as the patient's blood was seemingly incompatible with all ABO blood groups. Further investigation revealed the patient's blood group to be a rare subtype of the A group known as A2+veB. This article highlights the need to be aware of such rare subgroups, especially in tertiary referral centers, where unbooked Obstetric emergencies are encountered on a regular basis, so lifesaving measures can be appropriately taken.

KEYWORDS: Rare blood group, DIC.

INTRODUCTION: Two principal subgroup of blood group A are A1 and A2. In Indian population the frequency of $\mathrm{A} 2$ is $0.8-3.0 \%$, while the frequency of $\mathrm{A} 2 \mathrm{~B}$ is $0.6-1.4 \%^{2} .22-26 \%$ of $\mathrm{A} 2 \mathrm{~B}$ individuals can have anti $\mathrm{A} 1$ antibodies that react a temperature below 25 degrees and cause hemolytic transfusion reaction ${ }^{1,2}$. We present a rare case of an A2B positive blood group with postpartum hemorrhage, DIC in hypovolemic shock. An emergency request for blood transfusion created confusion in determining the exact blood group of the patient. This article highlights the need to be aware of such rare blood groups and using anti A1 lectin as a standardized protocol to prevent blood group incompatibility.

CASE REPORT: A 21 years old, female, referred from MIMS, Mandya as Para 2 living 2 delivered at $3 \mathrm{pm}$ at the Maddur government hospital with atonic PPH with shock in DIC. On examination patient had a feeble pulse and a BP of 80 systolic with a respiratory rate of 32 cycles/min. Her uterus was well contracted with minimal bleeding through the OS with $700 \mathrm{ml}$ of hematuria present.

The patient had already been managed medically for PPH and came to us on dopamine infusion drip and 2 pint PRBC of B +ve blood on flow. After stabilizing the patient, coagulation profile was found abnormal and 6pints platelets, 1 pint cryo and 4 pints FFP's was decided to be transfused.

But when blood was sent for cross matching, patient's blood group could not be ascertained. Hence FFP transfusion was withheld for the time being. At first, our blood bank could not determine whether the blood group was $\mathrm{AB}+\mathrm{ve}$ or $\mathrm{B}+\mathrm{ve}$. Then after further testing $\mathrm{A} 2 \mathrm{~B}$ blood group was confirmed. Since by that time patient had come out of shock and DIC further transfusions were avoided and her anemia was corrected with iron sucrose. The patient was discharged after 10 days of hospital stay.

Table 1: Different phenotypes of $\mathrm{ABO}$ in different races

\begin{tabular}{lcccccc}
\hline Blood group & $\mathrm{O}$ & $\mathrm{A}_{1}$ & $\mathrm{~A}_{2}$ & $\mathrm{~B}$ & $\mathrm{~A}_{1} \mathrm{~B}$ & $\mathrm{~A}_{2} \mathrm{~B}$ \\
\hline Caucasian & $44 \%$ & $33 \%$ & $10 \%$ & $9 \%$ & $3 \%$ & $1 \%$ \\
Black people & $49 \%$ & $19 \%$ & $8 \%$ & $20 \%$ & $3 \%$ & $1 \%$ \\
Asian & $43 \%$ & $27 \%$ & Rare & $25 \%$ & $5 \%$ & Rare \\
\hline
\end{tabular}




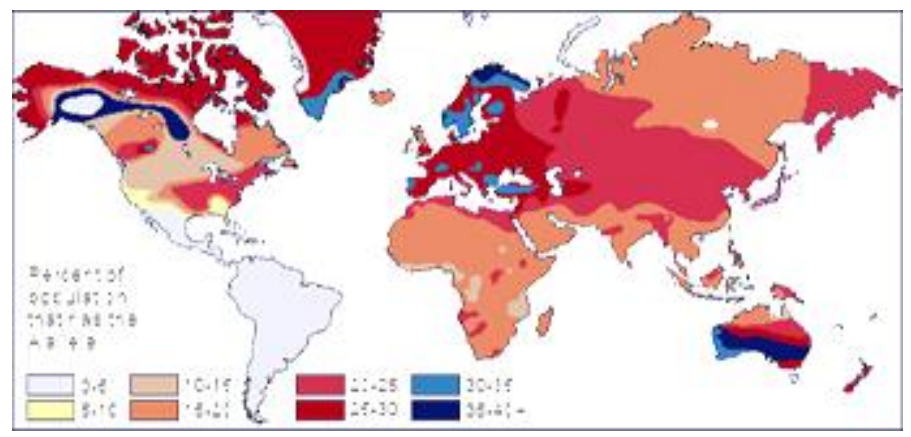

DISCUSSION AND CONCLUSION: ABO system antibodies arise shortly after birth on exposure to environmental agents for which antigenic makeup is similar to the $A$ and $B$ antigen found on human red blood cells (RBCs). The antibodies of the ABO system are primarily IgM in nature, although some IgG and IgA antibodies may also be present. The immune form of the $\mathrm{ABO}$ antibodies results from exposure to incompatible RBCs or other sources of ABO antigens. Most of the anti-A is of IgM type.

Thus, anti-A is able to agglutinate RBCs suspended in saline and activate complement with ease. It may cause rapid intravascular destruction of RBCs carrying the A antigen. Anti-A can be functionally divided into two forms: one form which reacts with A1 but not A2 cells (anti-A1) and another form which reacts with both $\mathrm{A} 1$ and A2 cells (anti-A common). ${ }^{3} \mathrm{~A} 1$ and A2 phenotypes are best differentiated using the anti-A1 (lectin) extracted from the seeds of the plant Dolichos biflorus. 4,5

Anti-A1, which is active in vitro at about $30^{\circ} \mathrm{C}$ but only dubiously active at $37^{\circ} \mathrm{C}$, will bring about the destruction of a proportion of $\mathrm{A} 1$ cells in vivo when a small dose of cells is injected. Those antibodies which are only dubiously active at $37^{\circ} \mathrm{C}$ would almost certainly fail to produce detectable $\mathrm{RBC}$ destruction following the transfusion of therapeutic quantities of blood.

On the other hand, in several instances in which anti-A1 has been active at $37^{\circ} \mathrm{C}$, extensive destruction of A1 cells in vivo has been recorded.

Boorman et al (1946) reported a case in which a patient of subgroup A2 was transfused with at least 7 units of A1 blood within a period of 4 days. Seven days after the last transfusion the patient became icteric and anemic and was found to have anti-A1 in her serum active at $37^{\circ} \mathrm{C}$. Several other examples of the development of anti-A1 active at $37^{\circ} \mathrm{C}$ following a series of transfusions have been described. ${ }^{6}$

Considering the lesser survival of $\mathrm{A} 1-\mathrm{RBCs}$ transfused to $\mathrm{A} 2 \mathrm{~B}$ or $\mathrm{A} 2$ persons, whose sera contain anti-A1,7 we propose to distinguish A1 and A2 subgroups in individuals with A and AB blood groups prior to blood transfusion, especially in those with a previous history of transfusion reactions following iso group blood transfusions.

Massive obstetric hemorrhage is a major contributor towards Maternal morbidity and mortality. Clinicians managing pregnant women should be equipped with the knowledge of blood and blood products and skills for managing massive obstetric hemorrhage ${ }^{8}$. Most of the individuals with a rare blood group are coincidently identified when a routine pre-transfusion testing or pregnancy follow-up is performed, if the antibodies corresponding to the rare specificity are present.

There is a growing awareness of the impact of the genomics revolution on transfusion medicine and its potential to transform the way blood is selected for transfusion. From antibodybased technology to now single-nucleotide polymorphism (SNP) genotyping for blood, PCR- 
technology will help in extended matching of RBC units. ${ }^{9}$ Such advances in cross-matching of blood can save the lives of many, especially, as in this case, young women of childbearing age and thus reduce maternal mortality.

\section{REFERENCES:}

1. Padmasri, Urvashi Bhatara, Rupa S. Iyengar; A rare case of A2+ve blood group in obstetric emergency, Journal of Clinical and Diagnostic Research. 2014 Feb; 8(2):181-182.

2. Chaudhari CN, Misra RN, Nagpal K. Transfusion in Blood Group A 2 B with Anti A 1 Recipient, MJAFI, 2008; 64( 4):371-72.

3. Kawahito S, Kitahata H, Kimura H, Tanaka K, Oshita S. Auto transfusion performed on a patient with cis AB blood group, British Journal of Anaesthesia 1999; 83 (3): 491-(2).

4. Rudmann SV. Textbook of Blood Banking and Transfusion Medicine $2^{\text {nd }}$ ed. Philadelphia: Saunders; 1995: 72-5.

5. American Association of Blood Banks. AABB News/American Association of Blood Banks Technical Manual. Vol 21. Bethesda: The Association; 1999: 180-6

6. Boorman KE, Dodd BE, Loutit JF, et al. Some results of transfusion of blood to recipients with "cold agglutinin. Br Med J. 1946: 751.

7. Cutbush M, Mollison PL. Relationship between characteristics of blood group antibodies in vitro and associated patterns of cell destruction in vitro. Br J Haematol. 1958; 4: 114.

8. Toufan M, SepasiF, Alizadeh A, Azarfarin R. Anesthesia for coronary artery bypass grafting with hypothermic cardiopulmonary bypass in a patient with a A 2 B negative Blood Group. ICJR journal 2008 ; 1(3): 185-186.

9. Brecher ME, editor. Technical Manual 14 th ed. Bethesda, Maryland. American Association of Blood Banks 2002.

\section{AUTHORS:}

1. Sudha R.

2. Lokeshchandra H. C.

3. Manjunath B. S.

4. Priya Ranganath

\section{PARTICULARS OF CONTRIBUTORS:}

1. Associate Professor, Department of Obstetrics and Gynaecology, Mysore Medical College and Research Institute Cheluvamba Hospital.

2. Professor and HOD, Department of Obstetrics and Gynaecology, Mysore Medical College and Research Institute Cheluvamba Hospital.

3. Chief Medical Officer, Blood Bank, KRH.

4. Post Graduate, Department of Obstetrics and Gynaecology, Mysore Medical College and Research Institute Cheluvamba Hospital.

\section{NAME ADDRESS EMAIL ID OF THE CORRESPONDING AUTHOR:}

Dr. Sudha R,

No. $12,3^{\text {rd }}$ Block,

$2^{\text {nd }}$ Stage, SBM Colony,

Srirampura, Mysore-570023,

Karnataka.

Email: drsudhaobgmmcri@gmail.com

Date of Submission: 09/07/2014.

Date of Peer Review: 10/07/2014.

Date of Acceptance: 30/07/2014.

Date of Publishing: 09/08/2014. 